\title{
La empresa informativa busca nuevos modelos de negocio
}

\author{
Pedro García-Alonso Montoya \\ Universidad Complutense de Madrid \\ pgarciaa@ucm.es
}

\begin{abstract}
Resumen:
El modelo de negocio tradicionalmente empleado en los medios informativos, basado en el cobro al lector o consumidor y en los ingresos publicitarios, resulta insuficiente para poder sostener la empresa informativa. Es necesario reinventar el modelo de negocio, buscando un sistema que permita a los medios subsistir en el nuevo mercado mediático online, con multiproducto y globalizado.
\end{abstract}

Palabras clave: Empresa Informativa; nuevo modelo de negocio; transformación.

\section{Media are looking for new business model}

\begin{abstract}
:
Old business model traditionally used in media, based on reader or consumer collection and advertising revenue is insufficient to sustain media companies. It is necessary to reinvent this business model to allow media survive in our new online multi-product and globalized media market.
\end{abstract}

Key Words: Media; new business model; transformation

\section{Referencia normalizada:}

García-Alonso Montoya, P. (2014): La empresa informativa busca nuevos modelos de negocio. Historia y Comunicación Social. Vol. 19. Núm. Especial Marzo. Págs. 729-741.

Sumario: 1. Introducción. Estado de la cuestión. 2. Metodología. 3. Necesaria transformación de las empresas informativas. 4. Asistimos a un cambio radical operado en los medios. 5. Estamos inmersos en la Nueva Era de la comunicación. 6. Hace falta implantar un nuevo modelo de negocio. 7. Conclusiones. 8. Referencias bibliográficas

A la vista de los actuales acontecimientos sucedidos en el mercado informativo, podemos afirmar que estamos asistiendo a un cambio en el modelo empresarial de las empresas mediáticas. El viejo modelo de cobro al consumidor y cobro al anunciante, ya no son la receta segura para asegurar la rentabilidad. Muchos datos negativos (cierres de cabeceras, Eres y despidos, deudas imposibles de asumir y otros datos desastrosos) nos obligan a reformular y a replantearnos la viabilidad del modelo de negocio periodístico. ¿A qué es debido este fenómeno? Al cambio radical operado en 
el sistema, tanto productivo (multiproducto), como de soporte (electrónico digital), de distribución (online por Internet) y de consumo (a la carta o personalizado). Como señala algún autor, fenómenos tales como "el periodismo ciudadano está transformando la relación entre los medios y sus audiencias" (Gonzalo, 2011).

\section{Introducción. Estado de la cuestión}

El entorno mediático ha cambiado radicalmente. Desde hace tiempo venían anunciándose estos cambios, pero ahora resulta innegable reconocer su presencia. El nuevo público joven, ya totalmente nativos digitales (Cfr. Marc Prensky, 2009), ha transformado el planteamiento imperante anterior, el existente desde la imprenta hasta la aparición de Internet.

Aunque la interactividad en televisión no es algo nuevo, el desarrollo de Internet y de la Web 2.0 han multiplicado las posibilidades con las que cuenta la audiencia para dialogar con el medio, más allá de la pantalla. Este hecho otorga especial importancia a modalidades participativas como el correo electrónico, el chat, el sms, los foros, los encuentros virtuales, las encuestas, los blogs o las redes sociales. En la actualidad, estas herramientas están siendo preferentemente incorporadas por las televisiones y dirigidas a un público joven, dada su especial predilección por los cambios y por el uso de las nuevas tecnologías. Esta comunicación analiza la incorporación de estas nuevas modalidades a partir de un estudio de casos centrado en las televisiones públicas autonómicas de España (Meso, 2011. Pág. 53).

Fenómenos tales como la digitalización total, el universal acceso a Internet disponible casi desde cualquier punto del mundo, el periodismo ciudadano libre y accesible a todos, la insostenible caída de los ingresos publicitarios en los medios, la gratuidad total del producto informativo online, la práctica eliminación de toda barrera de acceso -tecnológica, social, financiera- para crear un nuevo medio informativo, la distribución al consumidor sin coste a través de Internet, la aparición de nuevos segmentos de público y de nuevos submercados por doquier, la interacción del consumidor con el emisor, su implicación participativa en los mensajes, el nuevo papel informativo que desempeñan las Redes Sociales (Facebook, Linkedin, Twitter...), la instantaneidad de la recepción del servicio informativo a través de los nuevos soportes (tablets, smartphones, ipads...) son cambios que han causado una transformación radical en el modelo empresarial de los medios informativos.

Además, siendo la comunicación hoy absolutamente indispensable y necesaria para poder acometer cualquier tarea profesional del tipo que sea, tanto social como privada, colectiva o personal, resulta fundamental que la nueva empresa informativa sepa responder a estos retos, asumiendo el nuevo papel que el mundo actual le exige. Para lograrlo, es preciso que logre incorporar nuevas vías de negocio que sirvan para crear riqueza con su producto informativo, aportándole valor económico. 


\section{Metodología}

Para constatar científicamente el importante problema para el sostenimiento de los medios aquí planteado, hemos procedido metodológicamente de un modo sistemático. La investigación parte inicialmente de una revisión formal de los estudios y publicaciones recientes, producidos durante éste último decenio, por parte de estudiosos y expertos en el área científica de Empresa Informativa. También se han contrastado los datos con autores de referencia internacional, con probada validez, tales como Alfonso Sánchez-Tabernero, Robert G, Picard, Eli Noam, Michael P. Napoli... a quienes he podido entrevistar directamente bien en sus propias universidades de Columbia, Fordham o Navarra, o bien en Congresos Internacionales celebrados en Lisboa, Nueva York o Madrid.

Posteriormente donde puede verse en las opiniones de expertos que la situación es realmente preocupante. No se trata de un momento de crisis. No es sólo un paréntesis causado por la recesión, del cual acabaremos saliendo, para volver a trabajar según el modelo anterior. La transformación es radical, como prueban los escritos e investigaciones consultadas. Es tarea común de investigadores y de directivos. Como algún autor reseña, también los empresarios

buscan activamente un modelo de negocio que satisfaga el complejo entramado de intereses que afectan a productores, fabricantes de tecnología y software, distribuidores y anunciantes (...). Las cadenas de valor, los modelos de negocio y las funciones de las empresas están siendo cada vez más claras (...). . Otros estudios más recientes apuntan que los principales problemas de la industria siguen siendo la diversidad de estándares tecnológicos, la escasez de modelos de negocio; la inmadurez de la producción y la falta de apoyo de los anunciantes" (LEÓN, 2008). Es doctrina muy común en los autores que "las empresas de medios de comunicación revisan y amplían sus modelos de negocio (Campos, 2010).

\section{Necesaria transformación DE las empresas informativas}

Como hemos apuntado en el inicio, el viejo modelo empresarial tradicional, ese procedimiento seguido hasta ahora por las empresas informativas para conseguir monetarizar su actividad, adolece de fallos graves, ala vista de las actuales transformaciones. Uno de ellos es no lograr conseguir la rentabilidad necesaria. Se trata de algo tan sencillo como que sus gastos no superen a sus ingresos. Este requisito es absolutamente indispensable. Estamos ante una exigencia totalmente inexcusable para su continuidad, una condición básica para su mantenimiento, una obligación sine qua non que cumplir por cualquier empresa que desee perdurar. El nuevo público consumidor de los medios, al que se dirige la oferta informativa, ha cambiado sus horarios, sus hábitos, sus gustos, las necesidades que demanda satisfacer.

Hay diversificación de las audiencias, reestructuración de la oferta por las fusiones empresariales y hasta una nueva relación con la cultura letrada: se sigue leyendo, 
pero de otras maneras, y surgen nuevas articulaciones y diferencias entre lectores, espectadores e internautas (García Canclini, 2008. Pág. 27).

Son las audiencias, ellas mismas, las que están obligando a los medios a llevar a cabo un cambio total en su planteamiento empresarial, en su modelo de negocio, como sostiene ese célebre texto "Nosotros el medio": "Cómo las audiencias están modelando el futuro de las noticias y la información' (Bowman, 2003). El actual mercado mediático, digital y global, es también muy distinto: nuevas herramientas, mayor segmentación, efectividad y control total de la evolución de la oferta...

Las TIC abren un nuevo mercado de marketing dinámico, interactivo y promocional. La necesidad de las marcas de llegar a un consumidor cada vez más disperso entre una multitud de medios publicitarios, ha favorecido la aparición de nuevas herramientas de comunicación e información, capaces de segmentar de manera más efectiva los mensajes, medir la atención de la audiencia y calificarla, dirigirse al consumidor dónde y cuándo éste toma las decisiones de compra. Dado el actual entorno económico combinado con la intensidad de la competencia hace que cualquier inversión en medios por parte de los fabricantes esté sujeta a mayores controles de rentabilidad (Sendra, 2012: abstract).

Desgraciadamente, fenómenos tan negativos que hoy suceden en los medios, como la acuciante falta de inputs que sufren, especialmente en los ingresos publicitarios que constituyen, con mucho, la mayor fuente de su financiación-les preocupa mucho a los empresarios de la información. Es muy importante saber qué riesgos de viabilidad se corren al acometer la actividad empresarial.

A los analistas financieros les interesa, principalmente, saber cuáles son los posibles riesgos de la compañía, (...) viabilidad futura y necesidad futura del producto, así como posibles situaciones de crisis (Barquero, 2007: Pág. 62).

Hasta ahora, sin haber prácticamente variado casi nada durante siglos, estos dos ingresos fundamentales, como el pago del lector y la facturación publicitaria, habían bastado para asegurar la viabilidad del negocio periodístico. Así había venido sucediendo hasta hace muy poco. La información constituía un recurso escaso, por el cual cualquiera estaba dispuesto a pagar sin rechistar un precio de adquisición. $\mathrm{Su}$ valor era innegable. Información era poder. La gran fuerza competitiva de los medios estaba fuera de cualquier duda.

La noticia es el imán del periodismo. (...) La noticia es la materia prima que nutre a los diarios. (...) La cadena del éxito del periodismo parte con la noticia, que asegura la circulación. Una buen tiraje o rating, atrae publicidad. Y ambos elementos aseguran la viabilidad de los medios. La prensa prospera sobre esta formula (Sohr, 1998. Pág. 83).

Tristemente, ya no sucede así. Todo se ha transformado. Asistimos a una revolución mediática radical, que nadie sabe a dónde va a llevarnos. 


\section{Asistimos a un cambio radical operado en los medios}

El siglo XXI ha generado transformaciones profundas en el periodismo (...). La fórmula de negocio y de comercialización elegida, freemium, utility o metered, de micropayments o de franquicias (...) o, incluso, de pago total (menos viable), dependerá del plan de negocio, del potencial del grupo de comunicación que emprenda la aventura (el planteamiento de Orbyt o Kiosko y Más no puede ser el mismo que el de un diario digital local o comarcal) y la maduración del mercado. (Fondevila, 2012. Pag. 232).

Es opinión comúnmente compartida por los autores la radical importancia que la crisis actual ha supuesto para todo el sector de la prensa. Tanto la contracción económica, como la actual revisión del papel de los medios, no sugieren buenas perspectivas para este sector. Tenemos datos muy negativos que así lo confirman, tan ciertos e indiscutibles como los frecuentes cierres de cabeceras de diarios tradicionales, los muchos despidos y Eres echando a periodistas de los medios, las deudas astronómicas acumuladas que soportan muchos grandes grupos mediáticos... Son desgracias que nos llevan a cuestionarnos qué va a suceder con este modelo empresarial de negocio informativo.

Estas enormes consecuencias desfavorables, sufridas especialmente desde el año 2007, con la gran crisis publicitaria a escala mundial, por la gran deflación económica internacional que seguimos padeciendo, nos obligan a reconsiderar y a cuestionarnos seriamente las condiciones de permanencia del actual modelo de negocio periodístico. Es necesario buscar nuevas fórmulas empresariales que permitan sostener esta actividad, si realmente deseamos mantener el ejercicio empresarial de la información y de la comunicación.

Siendo realistas, hemos de admitir que el proceso informativo ha experimentado una transformación radical, abandonando su anterior favorable y dominante posición competitiva, antes tan rentable y ventajosa, gozando de su posición imperante como indiscutible cuarto poder, para pasar ahora a democratizarse, extendiendo su capacidad de acceso a todo el público que desee emitir su información por la Red.

Este fenómeno del periodismo ciudadano libre es tan cierto, que muchas redes sociales actúan en el mercado como producto sustitutivo de la información, sirviendo como contraoferta a las audiencias, como competencia ante los medios. Este cambio no afecta sólo a su sistema productivo, sino que también alcanza a sus nuevas vías de transmisión y difusión, a su forma de consumo, de acceso, de interacción participativa e integración y feedback entre el emisor y el receptor. El proceso informativo se ha reformado: ha pasado de ser unidireccional (sólo de ida), a ser bidireccional (de ida y vuelta); de monólogo, a diálogo; de información, a comunicación. Se han superado aquellas

características de los medios tradicionales, pero incorporando tanto un nuevo nivel de interacción como un nuevo modelo de negocio..... Internet como el metamedio que efectivamente ha sido capaz de prolongar a los medios de comunicación convencionales (Aguado, 2009. Pág. 41). 
Son muchos los factores que han intervenido en estos cambios. Sin ánimo ni intención de agotar la lista, cabe destacar fenómenos tales como la total digitalización, el acceso universal a Internet para el periodismo ciudadano, la caída de los ingresos publicitarios debida a la gratuidad total del producto informativo online, la eliminación de las barreras de acceso para la libre creación de medios informativos, el coste mínimo de distribución y de difusión universal por Intenet, la aparición de nuevos mercados emergentes y accesibles por todo el mundo, la implicación del consumidor en la respuesta interactiva a los mensajes, la proliferación de Redes Sociales como Facebook, Linkedin, Whastapp, Twitter... la instantaneidad de la recepción del contenido informativo a través de tablets, smartphones, ipads...

Todas estas transformaciones son la causa de la aparición de un nuevo modo y modelo periodístico que nadie puede negar. También ha provocado un cambio radical en la estructura de negocio en la empresa informativa, hacia lo que alguno se atreve a calificar de "Modelo de negocio inestable" (Albornoz, 2011):

Un tercer factor endógeno, que atinge al conjunto del sector de la prensa online, es la práctica ausencia de exitosos modelos de negocio. Esto lleva a las editoras a rentabilizar su presencia en la Red, a través de la búsqueda de diversas fuentes de ingresos: desde los clásicos reclamos publicitarios y anuncios clasificados, hasta la venta de contenidos a clientes finales o a otras empresas periodísticas (Albornoz, 2005).

Este problema es mundial, pues aunque no incide por igual en todos los países, tarde o temprano acabará por afectar a todos los medios informativos, en cualquier país o continente donde estén, tanto para los ciudadanos y entes privados, como para los organismos y mandatarios públicos. Algún autor denuncia que

la falta de interés de los gobiernos por impulsar la radio digital coincide con la estrategia de las grandes cadenas, que carecen de un modelo de negocio para aprovechar la nueva tecnología (Arboledas, 2011).

\section{Estamos inmersos en la Nueva Era de la comunicación}

No podemos olvidar que estamos inmersos en un nuevo milenio de nuestra era, al que le caracteriza la comunicación global que poseemos. La transformación sufrida en este nuevo ciclo, ha sido muchísimo más radical que la provocada por el invento de la imprenta hace cinco siglos. Actualmente estamos totalmente absorbidos por la nueva época de la comunicación total: gratuita, inmediata, directa, fácil, universal, omniabarcante... Se trata de un avance, sin posibilidad de retroceso. Usabilidad, ubicuidad, accesibilidad y conectividad son propiedades en las que Internet ha desbancado a los medios tradicionales, y que nadie está dispuesto a abandonar.

Todo junto, fácil y accesible a golpe de click. Conectividad, accesibilidad, ubicuidad y usabilidad son ventajas en las que la Web supera a los medios tradicionales (Campos, 2010. Pág. 23). 
Comunicarnos es hoy totalmente imprescindible. La transmisión y la interacción son hoy absolutamente necesarias para cualquier tarea que se plantee: relaciones privadas, trabajo, entretenimiento, localización, comercio, enseñanza, política... Eso provoca que la comunicación ocupe hoy un puesto indiscutible y un lugar fundamental en toda nuestra actividad personal, profesional, social, informativa...

En el caso de la empresa informativa, la nueva situación en la que tiene que desenvolverse no ha quedado ajena a estas alteraciones. Son poquísimos los medios que puedan hoy pretender seguir facturando ingresos a costa únicamente de su público consumidor y de sus anunciantes. Es necesario reinventar nuevas vías de crear riqueza mediante el su valor informativo. Tal es el caso de emisoras radiofónicas, que a pesar de ser absolutamente deficitarias y ausentes de lucro alguno, estando carentes de cualquier ingreso por la prestación del objeto de negocio propio suyo -el radiofónico- (como pago del oyente o cobro al anunciante), logran sin embargo mantener su rentabilidad sirviéndose de otros ingresos. Vaughan Radio en Madrid, un ejemplo muy singular, obtiene sus ingresos gracias a los cursos de idiomas que oferta y a las publicaciones educativas que factura, a pesar de estar constantemente facilitando totalmente gratis lecciones de inglés al oyente, tanto online como en antena.

Estos nuevos modelos de negocio, los que las empresas informativas deben adoptar, serán digitales, o no serán. El modo de proceder de las audiencias se ha transformado radicalmente. Hoy todo el público quiere recibir el producto singularmente y a la carta, en su pantalla, inmediato y gratuito: nada de negocios de masas. Es una sentencia firme: "Business models are digital". Es condición previa de un servicio, su accesibilidad al consumidor. Insistir en lo offline, no es ya mentenible:

Uncertainty in past years triggered by digital migration is giving way to a sharper focus on identifying, choosing and executing the business models, organisational structures and skill sets to harness new consumer behaviours and deliver rising future value (Fenez, 2011).

Es indiscutible que todas las transformaciones hasta aquí mencionadas se refieren sólo a los mercados desarrollados y maduros, a las economías de los países del primer mundo, con público culto y avanzado. Pero en otros países menos poderosos, aún emergentes o del tercer mundo, este fenómeno de transformación mediática sigue otro ritmo, muy distinto. Faltan aún muchos años para que puedan llegar a transformarse al nivel que aquí estamos comentando. A pesar de eso, no se le puede tampoco restar importancia a todo este tercer mundo, ya que afecta a muchos millones de personas, que además son aún la mayor parte de la población del planeta, siendo también precisamente quienes cuentan con mayor índice de natalidad y de crecimiento. En cualquier caso, la transformación de los medios avanza a ritmos de velocidades diferentes, según los países de los que hablemos.

The newspaper publishing segment illustrates diverging trends across mature and growth economies. There will be ongoing declines in some territories such as the United States (declining 1.4 percent compounded annually to 2016, and expected to be worth 43.8 percent less in 2016 than 2007), but strong growth in countries where the digital infrastructure is less mature, such as Argentina (11.9 percent growth 
compounded annually to 2016), Indonesia (11.2 percent), and India (9.6 percent) (Fenez, 2011).

\section{Hace falta implantar un nuevo modelo de negocio}

Hoy nos hallamos ante una paradoja sorprendente: los medios quedan mucho más accesibles que nunca, además de ser mucho más necesarios, pero sin embargo están viendo cuestionada muy seriamente su viabilidad. Se suceden éxitos y fracasos, avances y retrocesos, lanzamientos y cierres, que no nos permiten augurar con claridad un futuro cierto. Jamás antes hemos dispuesto de más comunicación, ni tan accesible, fácil y gratuita como ahora, pero nunca había habido una crisis de tal envergadura, tan fuerte, en todo el mundo mediático. En todos los siglos de vida de la prensa, nunca se había cuestionado de una manera tan preocupante su sostenibilidad ni su viabilidad, con un planteamiento tan radical como el de ahora nos hacemos. Como afirma algún autor:

Encontrar fórmulas de viabilidad para el periódico en papel es una tarea y una preocupación de los editores diarios en la última década, caracterizada por la paradoja de ser a la vez la etapa de mayor flujo y facilidad de acceso a la información y los años de mayores desastres (Túñez, 2009).

Para encontrar una solución que permita a la empresa informativa seguir actuando en el mercado de la comunicación, es imprescindible analizar todos los nuevos sucesos acontecidos, buscando nuevos sistemas que permitan conseguir crear riqueza económica con el producto informativo. A golpe de vista, nos encontramos con unos cuantos nuevos sistemas de financiación, tales como integrar la audiencia creando una comunidad que satisfacer con nuestra oferta informativa, o servirse del outsourcing, del e-learning, del e-commerce, del crowdfunding, de la suscripción por Pay Per View o del servicio a la carta, u otros modelos, que ofrecen claras vías, libres y abiertas, susceptibles de sostener las actividades profesionales de los informadores.

Tal como algunos indican, el sistema tal vez más sencillo podría ser el simple pago del usuario o consumidor. Ante la gran oferta que Internet brinda, intentar que el público pague por la información ofrecida, mientras pueda satisfacerla gratuitamente por cualquier otra vía, obliga a aportarle un valor y una calidad muy singulares. La prensa tradicional generalista, de masas, debe reajustar su oferta, para poder cobrar por ella. Eso sólo lo conseguirá añadiendo algo más atractivo que las meras copias de las agencias de noticias. Se trata de ofrecer un contenido de calidad, que verdaderamente interese a un segmento del público. En definitiva, menos medios globales y generalistas, "de masas", ofreciendo lo mismo para todos, y más medios especializados, dirigidos a determinados segmentos de la audiencia. Hay quien

argüía que detrás de los medios de comunicación de masas ya no había masas, una observación que resume bastante bien los fenómenos migratorios de las audiencias. 
(...) Sin embargo, [sistemas como] el satélite ofrece un nuevo modelo de negocio basado en la subscripción y, en principio, sin publicidad (Solana, 2010).

Como recuerda el refrán, la necesidad aguza el ingenio. Muchas empresas informativas tratan de vislumbrar nuevos modelos de negocio, ensayando nuevas formas de obtener rentabilidad, sin quedarse paradas ante la crisis que afecta tanto a su público lector, como a sus clientes anunciantes. Así lo apunta Weezel (2009):

It is generally accepted that newspaper firms are passing through hard times. Readers and advertisers - their 2 main income sources - seem to be turning to other media, thus negatively affecting newspaper financial performance.

De este modo, muchas empresas periodísticas están adoptando nuevas medidas estratégicas con importantes cambios organizacionales:

These organizational changes (i.e., integration and outsourcing) are affecting performance. The study shows that the higher the degree of integration within the firm, the more positive the performance" (ibid.). Con todo, este autor desrecomienda según su estudio el outsourcing como modelo que adoptar: "Outsourcing is found to have a negative impact (ibid.).

En cualquier caso, el gran problema que hemos de resolver está en encontrar un modelo de negocio que haga sostenible mantener la actividad propia de la empresa informativa. En el Paley Council for Media -el principal foro independiente para la industria de los medios de comunicación en los Estados Unidos- (IC2012) celebrado en 2012 en Madrid, se escucharon comentarios sosteniendo que "el periodismo se enfrenta al reto de mantener la calidad, mientras busca la receta de la sostenibilidad, en un entorno tecnológico cambiante".

En este mismo foro se hablaba de "el renacimiento del periodismo". Se comentó algo sobre los nuevos modelos de negocio, pero en realidad el tema principal abordado fueron los contenidos. Algún experto de indudable autoridad, como Andrew Rashbass, consejero delegado de The Economist Group, sugería dotar a los contenidos de tres cualidades vitales: el valor, la relevancia y la diferenciación.

Otros directivos, como Katharine Viner, subdirectora de The Guardian, sostenían que el panorama completo únicamente se puede mostrar con la combinación que surge del periodismo profesional y de la implicación activa de los lectores. También John Paton, consejero delegado de Digital First Media Wadah Khanfar, presidente del think tank Sharq Forum, sugería como trilogía el contexto, la profundidad y la priorización. Por otra parte, Richard Gingras, responsable de productos informativos de Google, sostenía que "las noticias no son necesariamente ciertas porque las cuenten los medios tradicionales" (El País, 26/04/2012). 


\section{Conclusiones}

¿Estamos ante la desaparición de los medios? ¿Está muerta la prensa? ¿Veremos pronto a la desaparición del periodismo? ¿Contemplaremos el cierre definitivo de las cabeceras tradicionales impresas? Hay quien lo sostiene afirmando: "Examining the news. Many now argue that print news media is dead. (...) Yes, the printed word might be dying, but the influence of the digitally reproduced word continues to grow" (Kenix, 2011).

Con todo, también existen motivos poderosos para discrepar de que vaya a suceder esa hecatombe. Por mostrar sólo un caso, una empresa informativa, que lo es, como Google, crece sin parar. Tal vez deberíamos entonces aclarar un poco los conceptos. Otros grandes empresarios de la Red están haciendo su fortuna sirviéndose de la comunicación online. Hay muchos casos de empresas informativas que están aprovechando la crisis para adquirir medios hundidos, casi gratis y a precio de liquidación.

While citizens around the globe lament the loss of the printed work, Rupert Murdoch, managing director of media conglomerate News Corporation, has quickly amassed about 200 newspapers in addition to his magazines, music studios, radio stations, sporting franchises, movie stdudios, television stations, broadcast companies, satellite televison comanies, cable channels, outdoor advertising agencies and moer. News Corporation continues to buy news papers because even if the transmission of some printed words move from paper to pixels, the power of words to transform society remanis perpetually Sorong (Kenix, 2011).

Es posible que el truco esté en saber distinguir dos conceptos muy parecidos: los medios de masas, los llamados 'mass media' o empresas informativas, por una parte, y las empresas de comunicación, por otra. Se trata de dos fenómenos parecidos, pero diversos. Sus modelos de negocio son radicalmente diferentes, especialmente en sus vías de financiación. "Este es el objetivo: revisar la proposición de valor de las empresas mediáticas a través de la reformulación de sus modelos de negocio y gestión" (Campos, 2011). En este punto es dónde el viejo debe aprender del nuevo, incorporando las nuevas técnicas empresariales para crear su nuevo modelo de negocio, que sea verdaderamente viable, rentable y sostenible.

\section{Bibliografía}

AGUADO GUADALUPE, Guadalupe; GARCÍA GARCÍA, Alberto Luis (2009): Del Word-of-mouth al Marketing viral: aspectos claves de la comunicación a través de redes sociales, 2009, en Comunicación y hombre: revista interdisciplinar de ciencias de la comunicación y humanidades, $\mathrm{N}^{\circ} .5$ (Ejemplar dedicado a: Nuevas tendencias en la comunicación social), págs. 41-51.

ALBORNOZ, L. A. (2011): Prensa digital: características de los principales diarios online en español - Revista ALAIC 2011 http://alaic.net/revistaalaic/index.php/ alaic/article/viewFile/168/160 [22-09-2013] 
ALBORNOZ, L.A. (2005): Los diarios online de información general. El caso de los grandes periódicos en español. Tesis Doctoral. Madrid. Universidad Complutense de Madrid. http://www.eca.usp.br/associa/alaic/revista/r4/ccientifica_02.pdf [22-09-2013]

ARBOLEDAS, L. (2011): La radio española: un negocio analógico en la era digital, en Revista Eletronica Internacional de Economia Política da Informação, da Comunicação e da Cultura 2011 http://www.seer.ufs.br/index.php/eptic [22-092013]

BARQUERO CABRERO, José Daniel y FERNÁNDEZ, Fernando (2007): Los Secretos del Protocolo, Las Relaciones Públicas y la Publicidad, Lex Nova, Valladolid, 363 págs.

BOWMAN, Shayne y WILLIS, Chris (2003): Nosotros el medio. Cómo las audiencias están modelando el futuro de las noticias y la información, [Tit. or.: We the media], The Media Center at the American Press Institute, Julio www.hypergene. net/wemedia/ 68 págs.

CAMPOS FREIRE, Francisco (coord.): El cambio mediático, Ed. Comunicación Social, Zamora 2010, 280 págs.

CAMPOS FREIRE, Francisco (2011): "Las empresas de medios de comunicación revisan y amplían sus modelos de negocio", en Razón y Palabra, México, http:// www.razonypalabra.org.mx/N/N74/VARIA74/16FreireV74.pdf [22-09-2013]

FENEZ, Marcel (Entertainment \& Media, PwC) (2012): "The End of the Digital Beginning: Challenge for Media Companies now Lies in How to Implement their Digital Strategies", en PWC, 12-Jun-2012, http://press.pwc.com/GLOBAL/ News-releases/the-end-of-the-digital-beginning-challenge-for-media-companies-now-lies-in-how-to-implement-their-d/s/adc065f9-5c63-451 f-81e483b4f0eb70a1 [22-09-2013]

FONDEVILA GASCÓN, Joan Francesc (2012): “La prensa digital en España: ¿Un negocio viable para emprendedores?", capítulo en El Periodismo Digital analizado desde la investigación procedente del ámbito académico, Zaragoza, pp. 231-243, 361 págs. http://www.academia.edu/3209145/La_prensa_digital_en_ Espana_un_negocio_viable_para_emprendedores [22-09-2013]

GARCÍA CANCLINI, Néstor (2008): "Libros, pantallas y audiencias: ¿qué está cambiando? en Revista Comunicar", n ${ }^{\circ}$ 30, Universidad de Huelva, pp. 27- 32, en www.revistacomunicar.com/verpdf.php?numero $=30$ [22-09-2013]

GONZALO, Paula (2011): "El periodismo ciudadano está transformando la relación entre los medios y sus audiencias", Blog Periodismo Ciudadano, 19 mayo. http://www.periodismociudadano.com/2011/05/19/el-periodismo-ciudadano-esta-transformando-la-relacion-entre-los-medios-y-sus-audiencias/ [22-09-2013]

KENIX, Linda Jean (2011): Alternative and Mainstream Media: The converging spectrum, Capt. "Movin beyond dfinitional limitations", 224 págs., en http:// books.google.com/books? id=SBjKfLtd4NIC\&pg=PT46\&lpg=PT46\&dq=\%22 model + of + business $\% 22+$ media\&source $=$ bl\&ots $=$ SRftLSkvAw\&sig $=\mathrm{iMsKV}$ T3SG9LjA8Q_Am9ExybkyM\&hl=es\&sa=X\&ei=aaUJUM-WD-rK6wGNw- 
$\mathrm{mcCg} \&$ sqi $=2 \& v e d=0 \mathrm{CFAQ} 6 \mathrm{AEwBQ} \# \mathrm{v}=$ onepage $\& \mathrm{q}=\% 22 \operatorname{mode} 1 \% 20 \mathrm{of} \% 20$ business $\% 22 \% 20$ media\& $\mathrm{f}=$ false [22-09-2013]

LEÓN ANGUIANO, Bienvenido (2008): "La visión de los productores sobre la televisión interactiva: el final de la utopía", en Comunicación y Socidad, vol. XXI, No1 / 2008, http://www.unav.es/fcom/comunicacionysociedad/es/articulo. php?art_id=41 [22-09-2013]

MESO AYERDI, Koldobika y LARRONDO URETA, Ainara (2011): “Cambios en las estrategias de las audiencias de las páginas web de televisión. Análisis de la participación en los entes públicos autonómicos en España", Libro Nuevos Medios, Nueva Comunicación, Salamanca, II Congreso Internacional Comunicación 3.0, pp. 53-68, en http://comunicacion3punto0.files.wordpress.com/2011/05/ comunicacion3punto0libroactas2010.pdf [22-09-2013]

PRENSKY, Marc (2009): "From Digital Immigrants and Digital Natives to Digital Wisdom H. Sapiens", en Innovate, Feb-Mar 2009, en http://www.innovateonline. info/pdf/vol5_issue3/H._Sapiens_Digital__From_Digital_Immigrants_and_ Digital_Natives_to_Digital_Wisdom.pdf [22-09-2013]

SENDRA GARCÍA, Francisco Javier (2012): La eficiencia de las tecnologías de la información y comunicación en la comunicación de la promoción de ventas en productos de gran consumo, Tesis doctoral dirigida por Francisco García García, María Luisa García Guardia, Francisco Martínez López, Madrid, 688 págs. Biblioteca Digital Complutense.

SOHR, Raúl (1998): Historia y Poder de la Prensa, Ed. Andrés Bello, Santiago de Chile 269 págs.

SOLANA, D. (2010): Internet: el medio rey, en Telos: Cuadernos de comunicación e innovación 2010

TÚÑEZ LÓPEZ, M. (2009): "Jóvenes y prensa en papel en la era Internet: Estudio de hábitos de lectura, criterios de jerarquía de noticias, satisfacción con los contenidos informativos y ausencias", en Estudios sobre el mensaje periodístico 2009, pp. 503-524

VV.AA. (2012): El País, Sociedad, 26/04/2012 http://sociedad.elpais.com/sociedad/2012/04/26/actualidad/1335471530_459284.html [22-09-2013]

WEEZEL, Aldo van [University of the Andes, Santiago] (2009): Organizational Changes in Newspaper Firms and Their Relation to Performance, JMM - The International Journal on Media Management, Vol 11, No 3/4 (2009).

\section{El autor}

Profesor Contratado Doctor en la Universidad Complutense de Madrid desde 2004, Acreditado a Titular (2011) por la A.N.E.C.A., Doctor en Periodismo por la Complutense (1995). Doctor en Filosofía (1990) y en Ética (1994) por Navarra y Master MBA por el Instituto de Empresa de Madrid (1992). Miembro en 30 años de once centros universitarios: Fordham University y Donald McGannon Communication Research Center de Nueva York, Instituo IECO de Valencia, Universidad Educa- 
tis de Suiza, Universidad San Pablo-C.E.U., Universidad de País de Gales-E.B.S., C. U. Villanueva, Universidad Europea de Madrid-CEES, Escuela Superior de Marketing y Negocios M\&B de Madrid, U.N.E.D.-Bizkaia y Universidad de Navarra. 31 Artículos publicados en Revistas universitarias; 30 Capítulos y 12 Libros; 15 Artículos material docente; 2 Tesis doctorales publicadas dirigidas y 3 Artículos de investigación dirigidos. Ha participado en ochenta Congresos, y dirigido 13 Tesis doctorales y otros 44 trabajos de investigación, con seis Proyectos de Investigación oficiales financiados. Blog con 1.236 artículos www.empresainformativa.com 